\title{
MEMAKNAI TRADISI UPACARA LABUHAN DAN PENGARUHNYA TERHADAP MASYARAKAT PARANGTRITIS
}

\author{
Abduc Jali \\ Taman Baca Masyarakat Delima Bantul \\ e-mail: jalil_kaya79@yahoo.co.id
}

\begin{abstract}
This article discusses the meaning of the "Labuhan Ceremony" and the effects on Parangtritis society. The research is based on the writer's experience as students' field project supervisor of Madrasah Aliyah Wahid Hasyim. The methodology used for this research is qualitative descriptive. Interviews, literature, brochures and media information were analyzed. It is concluded that according to Parangtritis people, the context of Labuhan ceremony is not only the myth of Queen of the South (Ratu Kidul), but they also believe that the most important context of the "Labuhan Ceremony" is grateful towards the God who was supreme over the devolution of grace. Labuhan has effects on their belief, economis, and safety.
\end{abstract}

Tulisan ini mendiskusikan makna tradisi upacara labuhan dan pengaruhnya bagi masyarakat Parangtritis. Penelitian ini dilatarbelakangi oleh pendampingan penulis kepada siswa-siswi Madrasah Aliyah Wahid Hasyim sebagai tugas akhir berupa karya ilmiah berbasis field trip. Metode penelitian yang digunakan adalah kualitatif deskriptif. Pengumpulan data diperoleh dari hasil wawancara, literatur, leaflet, dan brosur. Hasil penelitian menunjukkan bahwa menurut masyarakat Parangtritis, Labuhan tidak semata-mata hanya mitos dari nenek moyangnya agar terhindar dari kesialan, tetapi Labuhan dilestarikan sematamata sebagai rasa syukur terhadap Dzat yang maha agung atas pelimpahan anugerah yang diterima. Selain itu, Labuhan memiliki pengaruh terhadap kepercayaan kepercayaan/agama, ekonomi,dan keamanan.

Keywords: tradition, Labuhan, Parangtritis, Parangkusumo 


\section{Pendahuluan}

Masyarakat Indonesia dikenal dengan masyarakat yang multikultural, selain terdiri atas berbagai suku bangsa dengan aneka ragam adat dan kebudayaan. Salah satu unsur kebudayaan yang berbeda adalah sistem religi. Pada umumnya, masyarakat Yogyakarta masih sangat kental dengan budaya religi, indikatornya adalah banyaknya wisata kultural berbagai upacara yang diselenggarakan pada setiap tahun oleh masyarakat, misalnya upacara Labuhan. Selain juga upacara Pisungsung Jaladri Bhekti Pertiwi oleh Keraton Yogyakarta. Woordward (1999:24) menyebutkan bahwa Yogyakarta sebagai kota magis di dunia modern dan merupakan replikasi dari struktur kosmos.

Keberadaan Keraton Yogyakarta menjadikan masyarakat yang tinggal di daerah Yogyakarta masih menjunjung tinggi nilai-nilai budaya dan tradisi. Sebagai bentuk upaya pelestarian tradisi, berbagai upacara dan ritual masih rutin dilaksanakan oleh masyarakat umum maupun pihak Keraton. Meskipun banyak dari kegiatan budaya tersebut terlihat hanya menjadi seremonial belaka, namun upacara-upacara tersebut masih tetap mendapat tempat tersendiri di hati masyarakat. Salah satu dari sekian banyak upacara adat yang dilakukan oleh pihak Keraton Yogyakarta adalah prosesi Labuhan. Upacara Labuhan tersebut merupakan salah satu upacara religi pada objek wisata Parangkusumo.

Pantai Parangkusumo merupakan pantai di pesisir selatan yang berdampingan dengan pantai Parangtritis dan pantai Depok. Pantai ini secara administratif berada di desa yang sama dengan Pantai Parangtritis di Desa Parangtritis, Kecamatan Kretek, Kabupaten Bantul, Daerah Istimewa Yogyakarta. Nuansa sakral sangat terasa jika memasuki kompleks Parangkusumo, wewangian kembang setaman dan juga wangi kemenyan yang dibakar dan dijual oleh beberapa penjual yang mudah ditemui di sepanjang jalan masuk pantai. Hal ini dikarenakan ada anggapan bahwa pantai Parangkusumo sebagai pintu gerbang menuju kerajaan penguasa Laut Selatan. Pengunjung lebih banyak pada Malam Selasa Kliwon atau Malam Jumat Kliwon menurut penanggalan Jawa. Dua malam ini selain sebagai hari banyaknya para peziarah di Situs Parangkusumo, juga banyak ditemukan para perempuan malam.

Di Parangkusumo dibangun sebuah cepuri, tempat yang merupakan tempat doa sebelum acara Labuhan yang sering dilakukan oleh pihak Keraton Yogyakarta pada hari hari tertentu. Di dalam cepuri tersebut, terdapat dua batu yang diyakini sebagai tempat duduk Panembahan Senopati dan Ratu Kidul yang kemudian disebut "batu cinta". Hal ini dikarenakan, tempat ini disebut sebagai pertemuan Raja Mataram pertama yakni Panembahan Senopati dengan 
Penguasa Pantai Selatan yakni Ratu Kidul yang mengikat suatu perjanjian yang berawal dari permintaan Panembahan Senopati terhadap Ratu Kidul untuk membantu dirinya mewujudkan menjadi penguasa Mataram. Hal tersebut disanggupi oleh Ratu Kidul namun dengan syarat agar Panembahan Senopati dan seluruh keturunannya mau menjadi suami Ratu Kidul. Akhirnya perjanjian itu menjadikan Keraton Yogyakarta sebagai Pecahan Kerajaan Mataram mempunyai hubungan yang erat dengan Penguasa Pantai Selatan.

Sampai dewasa ini, pada batu atau petilasan tersebut ditemukan taburan bunga serta serangkaian sesaji yang dibawa para peziarah. Pada tempat tersebut, diyakini bahwa setiap permohonan yang dipanjatkan disekitar batu cinta tersebut akan terkabul. Ziarah ke tempat ini juga diyakini banyak orang dapat melepaskan beban berat yang ada pada seseorang serta memberikan semangat yang lebih pada orang tersebut.

Tradisi upacara Labuhan memiliki hubungan yang erat dengan masyarakat Parangtritis karena menurut kepercayaan yang mereka anut, jika ritual Labuhan tidak dilakukan, maka akan terjadi hal-hal yang tidak diinginkan, misalnya hilangnya pengunjung karena terseret ombak, hasil laut yang merosot drastis, dan tenggelamnya awak kapal di laut. Dari Pengalaman yang terjadi pada masyarakat tersebut, maka masyarakat mempercayai bahwa laut merupakan salah satu sumber kehidupan yang diberikan oleh sang penguasa alam untuk masyarakat Parangtritis yang harus dijaga, dihormati, dan disyukuri. Penulis ingin mengkaji lebih jauh tentang makna pentingnya upacara Labuhan dan pengaruhnya bagi kehidupan sehari-hari.

\section{Metode Penelitian}

Penelitian ini menggunakan pendekatan deskriptif kualitatif untuk memaparkan hasil temuan di lapangan. Adapun teknik pengambilan data yang digunakan adalah wawancara sebagai data primer dan didukung beberapa data sekunder berupa literatur, leaflet dan brosur-brosur bahkan informasi dari media lain terkait upacara Labuhan sebagai data sekunder. Dari hasil wawancara ini kemudian dianalisis dengan pendekatan deskripsi kualitatif.

\section{Upacara Labuhan dan Kondisi Masyarakat Parangtritis}

Kata "Labuhan" berasal dari bahasa Jawa, yaitu labuh. Labuh memiliki artinya sama dengan larungan, yaitu membuang sesuatu ke dalam air yang mengalir ke laut. Kata "larung" juga berarti memberi sesaji kepada roh halus yang berkuasa disuatu tempat. Dengan demikian, kata "labuh" atau "larung" dapat 
diartikan membuang sesuatu ke dalam air yang mengalir sebagai sesaji kepada roh halus yang berkuasa di suatu tempat, seperti laut Parangkusumo.

Dalam Ensiklopedi Keraton Yogyakarta (2014:337) Labuhan adalah upacara membuang benda-benda keraton dalam bentuk tertentu ke Laut Selatan, Gunung Lawu, Gunung Merapi, dan tempat lain yang bersifat khusus. Benda yang dilabuh antara lain: 1) potongan kuku (kenaka) dari Sri Sultan yang dikumpulkan selama satu tahun; 2) potongan rambut (rikma) dari Sri Sultan yang dikumpulkan selama satu tahun; 3) beberapa potong pakain bekas milik Sri Sultan; 4) benda bekas milik Sri Sultan yang berwujud payung (songsong); 5) layon sekar, yaitu sejumlah bunga yang telah layu dan kering bekas bunga sesaji pusaka-pusaka keraton yang dikumpulkan selama satu tahun; 6) sejumlah barang yang sebagian besar terdiri dari kain. Upacara ini dilakukan pada saat hari kelahiran raja (Wiyosan Dalem) atau hari Penobatan Raja. Sehingga setiap terjadi pergantian raja akan terjadi pergantian waktu labuhan karena masing-masing raja berbeda waktu penobatannya. Maksud diadakan upacara Labuhan ini untuk keselamatan pribadi Sri Sultan, Keraton Yogyakarta, dan rakyat Yogyakarta.

Dalam sejarahnya, upacara Labuhan yang diadakan oleh masyarakat Parangtritis adalah pengaruh sosialisasi dari upacara ritual adat Keraton Mataram yang sebelumnya digunakan sebagai sistem politik untuk memberi kepercayaan kepada masyarakat bahwa panembahan Senopati hanya ingin kehidupan yang damai, adil, dan makmur. Sedangkan untuk memperoleh semua itu, panembahan Senopati dibantu oleh kanjeng Ratu Kidul yaitu ratu halus penguasa laut selatan. Setelah itu, mereka melakukan nikah spiritual yang akhirnya dari pernikahan itu akan mengikat seluruh raja-raja Jawa sebagai keturunannya. Akhirnya semua masyarakat percaya bahwa Kanjeng Ratu Kidul akan memberikan semua itu, jika masyarakat memberikan persembahan yang diwujudkan dalam bentuk upacara Labuhan sebagai rasa syukur kepadanya. Upacara tersebut dimaksudkan sebagai wujud politik balas jasa terhadap Nyi Roro Kidul atau Ratu Kidul. Akan tetapi, masyarakat ada yang mempercayai bahwa kanjeng Ratu Kidul hanya sebagai perantara syukur kepada Tuhan Yang Maha Esa, termasuk keluarga Keraton. Di sinilah terjadi sesuatu yang bias terhadap kepercayaan masyarakat Parangtritis (Gatut Murnitmo, dkk, 2003: 12).

Menurut Keraton, upacara Labuhan adalah tradisi yang harus dilaksanakan untuk menjaga kelestarian alam. Labuhan mengandung makna bahwa sebagai manusia tidak boleh terus-menerus memberi residu kepada alam, tetapi juga 
harus menjaga kesucian keseimbangannya dengan mendaur ulang residu (Majalah Gema, edisi 9/Th III/2003, hlm. 11). Jadi tradisi yang biasanya dilakukan dengan melabuhkan pakaian Sri Sultan dan berbagai makanan ke laut adalah sebagai penghormatan kepada Nyi Roro Kidul, bukan kepada makhluk yang ada di Laut Selatan karena kanjeng merupakan gelar untuk alam (laut) agar tetap lestari.

Simbol "pakaian raja" dilabuhkan dengan tujuan pakaian raja yang didaur ulang karena pada dasarnya alam mempunyai sistem daur ulang. Misalnya, keunikan Keraton Yogyakarta yang terletak pada titik tengah laut dan Gunung Merapi, maka pakaian yang mengandung kewibawaannya pada saat itu tergantikan dengan pakaian yang lebih baik, yakni pemerintahannya lebih baik.

Disinilah Labuhan dimaknai sebagai sebuah upaya manusia untuk selalu ingat kewajibannya atas bumi yang telah memberikan ruang bagi segala hidup. Hal ini disimbolkan bahwa dengan dikembalikannya apa yang menjadi milik bumi melalui laut dan gunung yang merupakan dua lambang keseimbangan dan kesucian alam.

Pantai Parangkusumo di Bantul Yogyakarta biasanya dilaksanakan Labuhan secara besar-besaran tepatnya pada tiap 1 Sura. Hal ini dimitoskan adanya pertemuan Panembahan Senopati dengan Nyi Roro Kidul, berbeda dengan larung sesaji ke lautan hanya dilaksanakan secara sederhana. Berikut dipaparkan beberapa model Labuhan yang dilaksanakan oleh masyarakat Yogyakarta: 1) jika pada 1 Sura kondisi hujan, maka hanya dilakukan Labuhan oleh sekelompok kecil para peziarah, misalnya "melarung sesaji berupa tombak". 2) Beberapa warga Mayungan Potorono Wonosari yang melakukan tapa bisa, jalan kaki tanpa alas kaki tidak makan apa-apa, kecuali mengunyah gula jawa dan minum air putih serta berjalan kaki sepanjang $37 \mathrm{~km}$ menuju Parangkkususmo. Mereka datang ke Parangkusumo untuk mengisi alugoro - sebuah bentuk kayu semacam tombak. Dengan mengisinya melalui upacara Labuhan, kayu yang diyakini punya daya linuwih yang dapat menolak bala. Umumnya untuk menjaga keselamatan diri, alugoro selalu dibawa bekal terutama ketika merantau, atau dipasang di rumah untuk keselamatan keluarga. Selain itu, selama di pantai juga tidak boleh makan nasi, bahkan dilarang bicara. Semuanya diyakini oleh peziarah dan akan dapat melihat alam ghaib jika segala syarat bisa dipenuhi dan ritus berjalan mulus (Giyarno, 2006:88-90). 
Upacara labuhan yang menjadi tradisi masyarakat Keraton dan Parangtritis terbagi menjadi 2 (dua), yaitu:

1. Labuhan dari Keraton

Labuhan Ageng, yaitu labuhan yang dilaksanakan untuk memperingati lahirnya Sri Sultan, diperingati 8 (delapan) tahun sekali, tepatnya pada tahun dal. Jika dalam satu tahun sudah dilakukan Labuhan Ageng, maka untuk tahun tersebut Labuhan Alit ditiadakan. Pada saat Labuhan Ageng, benda-benda yang dilabuh dibagi menjadi empat bagian untuk dilabuh empat tempat yang berbeda, yaitu di Parangkusumo, Gunung Merapi, Gunung Lawu, dan Dlepih Kahyangan. Khusus Labuhan Ageng Gunung Lawu, barang yang dilabuh di tambah dengan sebuah payung yang disebut songsong pethak seret praos. Payung tersebut warnanya sebagian putih dan pada bagian lainnya berwarna keemasan. Adapun prosesinya adalah dimulai dari uburampe yang sebelumnya sudah disiapkan dan dibawa oleh abdi dalem Keraton ke Pendopo Kecamatan Kretek. Setelah itu, mampir di cepuri untuk melakukan doa bersama kemudian dilabuhi di pantai Parangkusumo. Isi dari uburampe adalah pakaian Sri Sultan dan nasi tumpeng, jajanan pasar, buah-buahan, berbagai macam bunga (mawar, melati, kantil, telasih, dan kenanga) yang sebagian merupakan bunga bekas sesaji di Keraton.

Labuhan Alit, yaitu Labuhan yang dilaksanakan oleh pihak Keraton. Biasanya dilaksanakan pada bulan Jawa yakni Jumadil Awal dan Jumadil Akhir. Misalnya Labuhan Alit Parangkusumo, tentu berbeda dengan dengan Labuhan Merapi maupun Labuhan Lawu yang dilaksanakan di gunung. Labuhan Alit Parangkusumo ini dilaksanakan di tepian pantai dengan iringan gamelan dan debur ombak serta suara angin yang bertiup. Wisatawan yang ingin mengikuti prosesi Labuhan Alit Parangkusumo tidak perlu berjalan naik, menerabas hutan guna sampai di kawah yang biasa digunakan untuk melarung sesaji, namun cukup mengikuti jalannya para abdi dalem dari bibir pantai.

Prosesi Labuhan Alit Parangkusumo biasanya diawali dengan penyerahan uburampe (perlengkapan) Labuhan oleh Kanjeng Raden Tumenggung Sumowijoyo selaku utusan Sri Sultan HB X kepada perwakilan Kabupaten Bantul di Pendopo Kecamatan Kretek sehari sebelum pelaksanan Labuhan Alit. Selanjutnya uburampe yang berupa barang-barang Sultan dan sesaji tersebut dibawa ke pendopo Parangkusumo sebelum akhirnya dibawa ke Cepuri Parangkusumo. Wisatawan yang ingin menyaksikan Labuhan ini bisa langsung menunggu di pesisir Pantai Parangkusumo. Dari tepi pantai Anda dapat melihat pergerakan iring-iringan abdi dalem yang membawa jodhang 
berisikan sesaji dan barang-barang Sri Sultan. Sesampainya di bibir pantai, barang-barang tersebut akan dihanyutkan di ombak yang menerjang pantai. Sesaat setelah barang-barang dilarung, masyarakat yang masih percaya tradisi ngalap berkah akan menceburkan dirinya ke laut guna mendapatkan bendabenda milik Sultan. Uburampe Labuhan tersebut dipercaya akan mendatangkan keberuntungan maupun penglarisan bagi siapa saja yang mendapatkannya.

2. Labuhan dari Masyarakat Parangtritis

Pisusung Jaladri Bhekti Pertiwi, yaitu upacara perwujudan rasa syukur masyarakat Parangtritis kepada Tuhan atas rizki yang dilimpahkan. Labuhan ini dilaksanakan oleh masyarakat Parangtritis setiap tanggal 5 dan 6 pada bulan Mei sampai Juni (setelah panen). Prosesinya adalah pada hari Senin Pon, masyarakat memasang sesaji ditempat keramat yang terletak di Desa Parangtritis (makam Syaikh Belabelu, Makam Syaikh Maulana Maghribi, dan di Cepuri). Kemudian pada hari Selasa Wage, diadakan Bhekti Pertiwi di pendopo Parangtritis dengan membawa sesaji dan doa bersama. Desain upacaranya adalah setiap RT membawa 1 (satu) jodhang persembahan kemudian diarak dari pendopo Joglo Parangtritis, selanjutnya dibawa bersama-sama ke pantai dan dilabuh di pantai Parangkusumo. Adapun sesepuh yang biasanya memimpin doa dan yang melabuh sekaligus, yaitu: pertama, Raden Panewu Surakso Tarwono, sesepuh dari Keraton dan juga juru kunci Cepuri; kedua, Raden Sumardi Jiwo Rejo dan Bapak Budi Asih Suparno, yaitu seorang penghayat kepercayaan Trisuka.

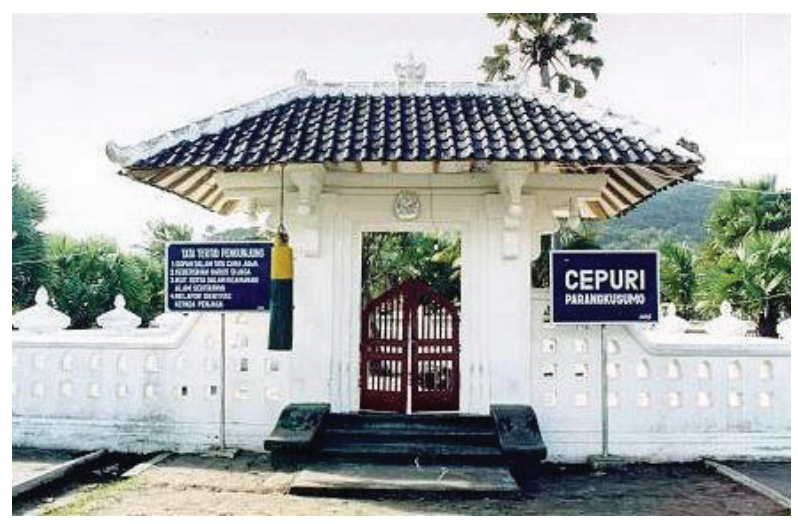

Gambar 1. Cepuri Parangkusumo

Sumber: kebudayaanindonesia.net 
Labuhan dari para nelayan adalah sedekah laut yang biasanya diadakan oleh para nelayan setiap tanggal 16 Februari. Labuhan ini diadakan di pantai Depok, tepatnya di Tempat Pelelangan Ikan (TPI) Bungkus.

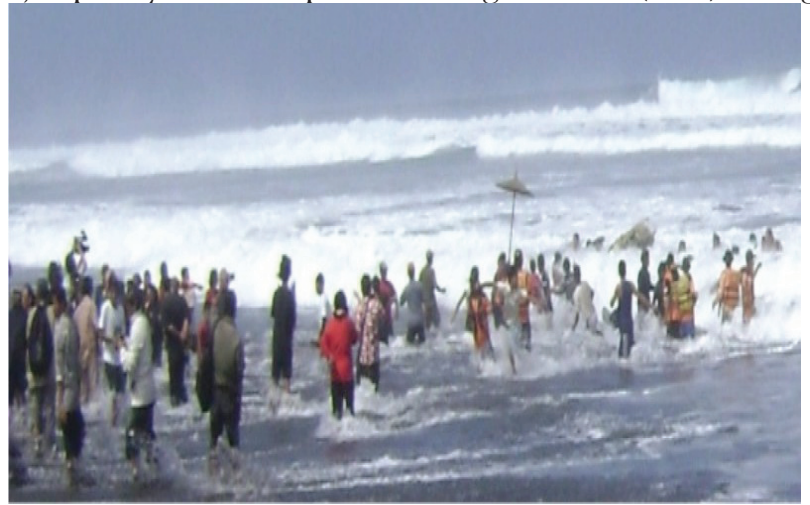

Gambar 2. Upacara Labuhan di Pantai Depok

Sumber: rri.co.id

Labuhan khusus orang Hindu (melasti sesaji), yaitu Labuhan yang diadakan oleh umat Hindu untuk menyambut datangnya hari Raya Nyepi. Upacara ini dilakukan setiap bulan Februari.

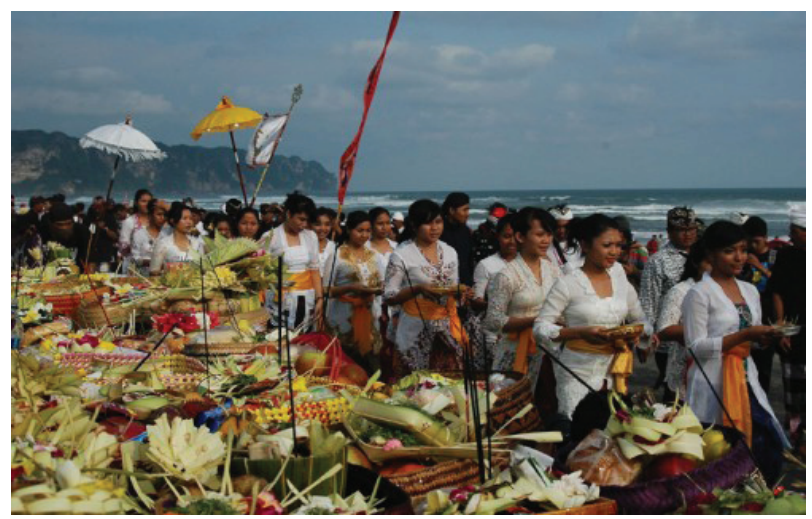

Gambar 3. Labuhan Melasti sesaji

Sumber: targetabloid.go.id

Labuhan dari Yayasan Hondodento, yaitu upacara yang dilakukan oleh Trah Hondodento dalam rangka permohonan keselamatan Nusa dan Bangsa. Biasanya diadakan setiap tanggal 15 Muharram oleh Yayasan yang pusatnya di Kediri Jawa Timur. 
Labuhan Peh Cun (hari Raya Twan Yang), yaitu tradisi masyarakat Tionghoa untuk mengenang legenda seorang kaisar Cina. Labuhan ini biasanya diadakan pada tanggal 5 bulan lima kalender imlek.

Upacara labuhan merupakan tradisi masyarakat Parangtritis yang telah lama membudaya, sehingga untuk menghilangkan tradisi semacam ini tidak mudah. Inti dari tradisi upacara ini adalah ungkapan rasa syukur kepada Tuhan Yang Maha Esa atas karunia yang telah diberikan, sekaligus sebagai ungkapan terima kasih kepada kanjeng Ratu Kidul dan para leluhur yang selama ini telah menjaga mereka agar tidak terjadi malapetaka, baik bagi generasi dewasa ini maupun generasi di masa mendatang (Wawancara dengan Kamrihadi, 10 Maret 2015).

Keadaan alam sekitar sangat mempengaruhi kehidupan masyarakat, dimana mereka tinggal. Pengaruh alam sekitar akan terlihat pada sistem mata pencaharian, teknologi pertanian, pola perkampungan serta adat istiadatnya. Melihat keadaan atau lingkungan Parangtritis yang sebagian besar berupa persawahan dan ladang, maka sebagian besar penduduknya bekerja sebagai petani, baik sebagai pemilik tanah atau buruh. Meskipun demikian, ada juga penduduk yang bekerja sebagai pegawai negeri, pedagang, buruh bangunan, dan abdi dalem.

Sebelum objek wisata berkembang, sebagian besar penduduknya mengandalkan dari hasil pertanian saja. Namun seiring dengan perkembangan objek wisata, maka terjadi pergeseran mata pencaharian. Selain petani, penduduknya juga melakukan pekerjaan sampingan, seperti: pedagang, baik berupa makanan-minuman, souvenir, menjadi tukang parkir, menyewakan tempat penginapan, menyediakan fasilitas kamar mandi dan Water Close (WC), menyewakan delman dan kuda.

Sebagaimana masyarakat Jawa pada umumnya, mayoritas penduduk Parangtritis masih melakukan tradisi lama dengan kepercayaan terhadap rohroh serta kekuatan gaib (supranatural). Sehubungan dengan upaya mewujudkan kesejahteraan, kebahagiaan dan ketenangan hidup masyarakat, maka pada waktu tertentu, mereka melakukan hal-hal yang bersifat keagamaan yang telah menjadi tradisi masyarakat.

Tradisi yang masih biasa dilakukan oleh masyarakat Parangtritis adalah berkaitan dengan daur hidup maupun tradisi yang berhubungan dengan pertanian dan ternak. Di samping itu, masyarakat masih kuat melaksanakan upacara-upacara adat yang berkenaan dengan daur hidup. Misalnya, upacara mitoni (saat kandungan ibu hamil umur 7 bulan), brokohan (pada saat kelahiran 
anak), perkawinan, kematian, budaya-budaya lokal yang lain, yang sampai dewasa ini masih dilestarikan.

Masyarakat Jawa merupakan masyarakat yang transenden, maka Labuhan diberikan untuk memberikan penghormatan kepada Tuhan, leluhur, dan spirit hidup lainnya. Sekaligus mengukuhkan harmoni kerukunan dalam komunitas sosialnya. Dalam menjaga harmoni sosial tersebut, seluruh prosesi upacara adat sangat berpern dalam menjaga dan mengukuhkan kewibawaan Keraton, karena bagi mereka Keraton adalah lembaga yang tidak saja memiliki posisi sangat kuat secara kultural, tetapi juga sangat berpengaruh secara sosial politik.

\section{Pengaruh Labuhan terhadap Masyarakat Parangtritis.}

Secara subyektif, ditinjau dari sudut pandang masyarakat Parangtritis sendiri, Labuhan berpengaruh secara signifikan bagi kehidupan masyarakat setempat. Dengan istilah lain, pandangan masyarakat Parangtritis terhadap Labuhan adalah keseluruhan semua keyakinan. Orang Jawa berpandangan bahwa realitas tidak dibagi dalam berbagai bidang yang terpisah satu sama lain, melainkan realitas dilihat secara utuh dan menyeluruh. Dari hasil pengamatan penulis, masyarakat yang melakukan labuh di sekitar petilasan Parangkususmo, bisa lebih khusyuk melakukan laku yakni prihatin, tirakat, dan tapa. Suasana yang sepi, menghantarkan para pelaku bisa lebih memusatkan pikir dan rasa. Berikut pengaruh Labuhan bagi masyarakat Parangtritis:

1. Bidang Keagamaan

Masyarakat semakin percaya bahwa upacara Labuhan yang mereka laksanakan akan mewujudkan segala sesuatu yang mereka inginkan, terutama bagi muslim mencoba menghubungkan labuhan dengan warisan lelehur ketika para wali menyebarkan agama melalui beberapa media, termasuk kesenian berupa wayang. Bagi agama lain, upacara Labuhan selain merupakan kekayaan budaya. Tokoh-tokoh agama juga merasa perlu untuk melestarikan upacaraupacara serupa, tidak hanya murni kebudayaan, tetapi dalam ajaran agamnaya terdapat-unsur-unsur dan misi kegamaan yang saling mendukung.

2. Bidang Ekonomi

Dari sisi positif, masyarakat berkeyakinan bahwa Labuhan yang dilakukan mempengaruhi keuntungan dalam hal pertanian dan penghasilan mereka. Dari sisi negatifnya, masyarakat tidak memperhitungkan masalah materi yang berakibat terjadi pemborosan karena membuang berbagai pakaian dan makanan. Lebih jauh, konsep bidang ekonomi, Labuhan dimaknai sebagai filosofi kesejahteraan 
ekonomi melalui pembangunan arah selatan. Pembangunan arah selatan bermakna perlunya menghidupkan kembali para nelayan agar sadar bahwa laut sumber kehidupan. Menggerakkan ekonomi nelayan juga patut dibarengi dengan teknologi yang canggih agar memaksimalkan penangkapan ikan. Bagi masyarakat sekitar, Labuhan merupakan lahan rezeki karena masyarakat dapat membuka berbagai jenis usaha seperti warung makan, penginapan, dan kamar mandi umum.

3. Bidang Keamanan

Masyarakat Parangtritis meyakini bahwa selama mereka rutin melakukan upacara Labuhan, maka desa mereka akan dijaga oleh Kanjeng Ratu Kidul. Sedangkan secara obyektif, ditinjau dari sudut pandang masyarakat luar, Labuhan diyakini sangat erat kaitannya dengan unsur kepercayaan yang berkembang di daerah pantai. Terjadi kepercayaan yang bias antara penerapan agama yang tumpang tindih dengan kelestarian budaya animisme (semua benda memiliki roh atau jiwa) dan dinamisme (semua benda memiliki kekuatan ghaib/kesaktian). Labuhan semakin melekat pada keseharian masyarakat Parangtritis pada budaya nenek moyang dengan pola pikir dan bias agama. Hal ini mempengaruhi cara pandang masyarakat Parangtritis, antara lain:

1. Keyakinan Bahwa Kanjeng Ratu Kidul hanya sebagai penghubung kepada Tuhan Yang Maha Esa;

2. Masyarakat yang percaya penuh dengan Ratu Kidul menyakini bahwa Ratu Kidul pemberi kedamaian dan ketentraman;

3. Kelepasan tanggung jawab dalam hal keamanan dan peruntungan pendapatan berdasarkan kesuksesan pelaksanaan labuhan.

Berbagai pengaruh Labuhan tersebut di atas, jika diamati secara sepintas dapat membuktikan pendapatan atau ekonomi mereka semakin meningkat, selain keamanan terjaga, namun dalam waktu yang bersamaan juga bisa sebagai wujud manifestasi optimisme masyarakat. Tanpa mereka sadari timbul usaha gigih dan optimal. Misalnya dalam mencari ikan, mereka gigih sehingga secara otomatis ekonomi mereka akan makmur. Selain itu, upacara Labuhan yang mereka laksanakan secara rutin akan menjadikan mereka merasa tentram damai karena masyarakat melakukan upacara dengan bersama-sama.

Bila ada peristiwa yang dialami, orang cenderung menghubungkannya dengan apa yang pernah terjadi sebelumnya. Tidak sedikit hal itu dilihat masyarakat Parangtritis sebagai suatu peringatan akan terjadinya sesuatu di masa datang. Sebut saja tindakan Mbah Marijan yang tidak mengindahkan himbauan 
pemerintah, yang diwakili Gubernur DIY sekaligus raja atau Sri Sultan HB $\mathrm{X}$, mengakibatkan meninggalnya Mbah Marijan. Konon Mbah Marijan lebih mampu membaca fenomena alam dibandingkan dengan sekedar himbauan masyarakat termasuk pemerintah, meskipun perintah raja untuk turun dan menjauh dari beberapa kilometer dari Gunung Merapi selalu disampaikan. Yang terjadi justru Mbah Marijan tetap masih di rumah, dengan keyakinan bahwa dia telah mendapat wangsit atau informasi dari alam, Gunung Merapi masih belum mengeluarkan wedus gembel, dan terbukti beberapa kali memang masih aman dan bagi mbah Marijan, tidak ada kewajiban untuk tunduk pada HBX, baginya predikat juru kunci untuknya adalah HB IX.

Barangkali fenomena yang dialami Mbah Marijan tersebut, adalah satu di antara sekian orang yang mencoba menghayati kembali pengalaman masa lampau serta menempatkan diri pada masa sekarang dan masa datang. Gejala meletusnya Gunung Merapi ditangkap sebagai isyarat dan tanda-tanda alam. Menurut Cassirer (1990: 41), manusia adalah animal symbolicum, yaitu binatang yang bermain dalam simbol-simbol. Dan tanda itu biasanya dihubungkan dengan kepercayaan yang disebut mitos (Prapta Diharja. J, 1995: 92-93).

\section{Simpulan}

Dari beberapa uraian di atas, dapat diambil kesimpulan bahwa sebagaimana masyarakat Jawa pada umumnya, penduduk Desa Parangtritis masih percaya terhadap roh-roh nenek moyang mereka serta kekuatan gaib lainnya sehingga mereka masih melakukan tradisi alam, sejenis tradisi Labuhan yang usianya sudah ratusan tahun. Upacara Labuhan yang dilakukan oleh seluruh masyarakat Yogyakarta, antara lain Labuhan Ageng, Labuhan Alit, Pisusung Jaladri Bhekti Pertiwi, Labuhan dari para nelayan, Labuhan Khusus Umat Hindu, Labuhan dari Yayasan Hendrodento, dan Labuhan Pen Chu. Dari masing-masing labuhan itu memiliki tujuan yang sama, yaitu memohon kesejahteraan hidup di dunia dan akhirat. Labuhan itu dilaksanakan dengan cara melabuh uburampe yang sudah disiapkan. Adapun uburampe yang akan di labuh adalah nasi tumpeng, jajan pasar, buah-buahan, dan berbagai macam bunga, namun bagi Labuhan yang dilakukan oleh pihak keraton, seperti Labuhan Ageng ditambahkan dengan pakaian Sultan. Setelah uburampe dilabuh, maka diperebutkan oleh para pengunjung yang memang hadir untuk ngalap berkah yang menceburkan diri. Begitu kuatnya kepercayaan masyarakat tersebut, sehingga berpengaruh bagi masyarakat Parangtritis. Pengaruh tersebut berpengaruh pada bidang keagamaan, ekonomi, maupun bidang keamanannya. 


\section{Daftar Pustaka}

Arinton, Pudja Soepanto.1990. Upacara Tradisional Labuhan Keraton Yogyakarta. Yogyakarta: Departemen Pendidikan dan Kebudayaan, Direktorat Jenderal Kebudayaan, Direktorat Sejarah dan Nilai Tradisional Proyek Inventarisasi dan Pembinaan nilai-nilai Budaya.

Ensiklopedi Keraton Yogyakarta. 2014 cetakan kedua. Yogyakarta: Dinas Kebudayaan DIY.

Gatut, Murniatmo dkk. 2003. Budaya Spiritual Petilasan Parangkusumo dan Sekitarnya. Yogyakarta: Wahyu Indah Offset.

Sholikhin, Muhammad. 2009. Kanjeng Ratu Kidul: Dalam Perspektif Islam Jawa. Yogyakarta: Narasi.

Sumarjiyanto. 2004. Mitologi Makam Syekh Maulana Maghribi di Parangtritis Bantul. Yogyakarta: Skripsi UIN Sunan Kalijaga Yogyakarta tidak diterbitkan

Utami, Sri Rahayu, Yoyok P. Maulana, Bimo Wijoseno, Eman Sulaiman, Mathe Fika, M. H Giyarno. 2006. Misteri-Cinta di Tempat Keramat, Nyi Roro Kidul, Malam 1 Suro, dan Jumat Kliwon. Jakarta: PT. Primamedia Pustaka.

Yusuf, Muhammad. 2006 Dunia Orang Parangkusumo: Studi Kasus Wong Wedok Nakal. Yogyakarta: Tesis UGM tidak diterbitkan.

Yuwono Sri Suwito, K.H.A Muhaimin, Bugiswanto, Sumarno, Ambar adrianto, Yustina Hastrini Nurwanti. 2006. Buku Pedoman Pelaksanaan Upacara Adat

Di Daerah Istimewa Yogyakarta. Yogyakarta: Dinas Kebudayaan DIY

Majalah Gema, edisi 9/Th III/2003, hlm. 11.

Brosur-brosur yang dikeluarkan oleh Jogja Tourisme Board. 